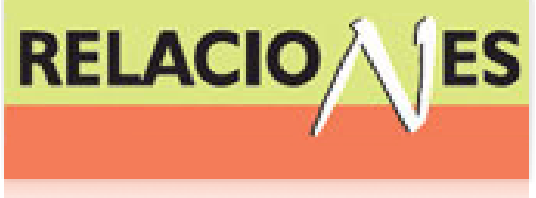

Relaciones. Estudios de historia y sociedad ISSN: 0185-3929

relacion@colmich.edu.mx

El Colegio de Michoacán, A.C

México

Gutiérrez Cham, Gerardo

Argumentación falaz en dos periódicos religiosos de Jalisco. Siglo XIX

Relaciones. Estudios de historia y sociedad, vol. XXXI, núm. 124, 2010, pp. 227-246

El Colegio de Michoacán, A.C

Zamora, México

Disponible en: http://www.redalyc.org/articulo.oa?id=13718469008

Cómo citar el artículo

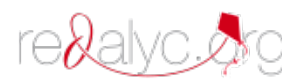

- Número completo

- Más información del artículo

- Página de la revista en redalyc.org

Sistema de Información Científica

Red de Revistas Científicas de América Latina, el Caribe, España y Portugal Proyecto académico sin fines de lucro, desarrollado bajo la iniciativa de acceso abierto 


\title{
ARGUMENTACIÓN FALAZ EN DOS PERIÓDICOS RELIGIOSOS DE JALISCO. SIGLO XIX
}

Gerardo Gutiérrez Cham*

\author{
Universidad de Guadalajara
}

\begin{abstract}
Este trabajo forma parte de una investigación en torno a estrategias argumentativas sobre discurso religioso en situación de confrontación y debate. El corpus de estudio está conformado por textos de 1874, publicados en dos periódicos jaliscienses de propaganda religiosa, uno católico: La Religión y la Sociedad, y el otro cristiano reformado: La Lanza de San Baltasar. Me interesa la perspectiva contrastiva de confrontación polarizada. La idea es mostrar el funcionamiento pragmático-discursivo de argumentos falaces que funcionaban como actos de habla especiales de "ataque" $\mathrm{y}$ "defensa". Teóricamente parto del modelo pragma-dialéctico de las falacias argumentativas (Grootendorst 2003; Anscombre y Ducrot 1988; Hamblin 1970). Mostraré cómo es que la defensa ideológica de prácticas y creencias religiosas podía ser reforzada desde las "periferias" de la racionalidad, mediante el predominio de argumentos falaces; de modo que los temas a discutir pasaban a segundo plano.
\end{abstract}

(Discurso, prensa, religiosa, argumentación, falacias)

\section{BREVES NOTAS CONTEXTUALES}

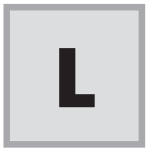

a guerra de Reforma había creado las condiciones mínimas para que las prácticas religiosas se diversificaran en México, y por consiguiente, en Jalisco. Desde 1870, los protestantes pudieron distribuir sus primeras publicaciones de propaganda. No fue una tarea fácil, ya que hasta ese momento la Iglesia católica aún mantenía fuertes nexos con las elites políticas y económicas del país. Este hecho puede verse como parte de un largo litigio religioso, que ya se planteaba en las sesiones constituyentes de 1824, donde se es-

*gcham535@yahoo.com.mx 
tablecía en el artículo $3^{\circ}$ que la religión católica debía ser la única permitida. Cito dicho artículo: "Artículo 3.- La religión de la nación mexicana es y será perpetuamente la C. A. R. La nación la protege por leyes sabias y justas, y prohíbe el ejercicio de cualquiera otra".${ }^{1}$ Como es de suponerse, con la aprobación de este artículo, cualquier intento oficial para tratar de institucionalizar otra religión distinta, inmediatamente quedaba al margen del pacto federativo.

En términos generales, aún en 1873, año en que se publicaron los periódicos que recojo en el corpus (La Lanza de San Baltazar y La Religión y la Sociedad) predominaban muchas fuerzas de interés, que privilegiaban a la religión católica por encima de cualquier otra. Las oligarquías políticas y económicas de la región consideraban que sólo dicha religión podía mantener la coherencia del tejido social. Además se consideraba que la religión católica debía mantenerse como patrimonio fundacional de una sola cultura nacional. Este hecho se vinculaba con la pretensión de que era posible instaurar una sola identidad, común y homogénea para todos los habitantes de México. Por lo demás, desde la jerarquía religiosa oficial, se había difundido la creencia de que cualquier religión que no fuera la católica, inmediatamente debía ser estigmatizada como "secta". Este hecho no es un detalle menor, pues con ello se implicaba que los protestantes eran disidentes, y que sus prácticas debían considerarse "falsas" y de origen espurio (Dorantes 2005). Sin embargo, toda vez que se desencadenó la Guerra de Reforma (1858-1861), específicamente en 1860, se formalizó un proyecto de ley, a través del cual quedaba establecida la libertad de cultos. De esta manera se abrió el camino para el ejercicio del culto protestante. Al mismo tiempo se fue generando un clima propicio para que surgieran las primeras publicaciones de propaganda cristiana reformada.

Antes de que hubiera publicaciones financiadas y promovidas por grupos reformados en Jalisco, ya había miembros de sociedades bíblicas o colporteurs que, entre otras actividades evangelizadoras, distribuían biblias, nuevos testamentos, y diversas obras de autores no católicos. En 1866, el primer Arzobispo de Guadalajara, Pedro Espinoza, preocupado

${ }^{1}$ Constitución de 1824. Tomado de: http: / / www.cervantesvirtual.com/ servlet/SirveObras/12148085130100492976402/p0000001.htm\#I_3_ 
por el proselitismo creciente de grupos protestantes asentados en la región, emite una carta advirtiendo a los fieles católicos contra las versiones reformadas de la Biblia. Precisamente, en el libro Los «otros» Hermanos Alma Dorantes $(2006,60)$ hace notar que durante los años posteriores a la Guerra de Reforma, uno de los grandes puntos de conflicto consistía en que la jerarquía católica pugnaba por que se prohibiera la impresión y circulación de traducciones luteranas de la Biblia. Este aspecto se manifiesta con mucha fuerza en el corpus, como puede evidenciarse en las muestras dedicadas al estudio de las falacias argumentativas.

El primer periódico protestante del país se publica en Zacatecas, en 1856. Se tituló La Antorcha Evangélica (Téllez 1995, 19). La publicación fue financiada y difundida por un grupo evangélico encabezado por el médico estadounidense Julio M. Prevost, quien había llegado a México junto con el ejército norteamericano. Esta y otras publicaciones se difundieron en Guadalajara. Durante la segunda mitad del siglo XIX aumentó considerablemente la literatura católica en contra de las ideas evangélicas, lo cual también puede verse como indicio de que estaba aumentando la propaganda protestante. Al respecto, Alma Dorantes $(2005,61)$ afirma lo siguiente: "A partir de finales de la séptima década del siglo, en el arzobispado de Guadalajara correrían ríos de tinta destinados a combatir, tanto la predicación de los disidentes como sus escritos". Uno de los combatientes más apasionados en contra del proselitismo protestante fue el presbítero Agustín de la Rosa, precisamente, a través de uno de los periódicos que conforman las notas analizadas: La Religión y la Sociedad.

El corpus de estudio está conformado por textos de 1874, publicados en dos periódicos jaliscienses de propaganda religiosa, uno católico: $\mathrm{La}$ Religión y la Sociedad, y el otro cristiano reformado: La Lanza de San Baltasar. Me interesa la perspectiva contrastiva de confrontación polarizada. La idea es mostrar el funcionamiento pragmático-discursivo de argumentos falaces que funcionaban como actos de habla especiales de "ataque" y "defensa". Teóricamente parto del modelo pragma-dialéctico de las falacias argumentativas (Grootendorst 2003; Anscombre y Ducrot 1988; Hamblin 1970). Mostraré cómo es que la defensa ideológica de prácticas y creencias religiosas discurría en las "periferias" de la racionalidad, y cómo, ante todo predominaba el uso de argumentos falaces, 
lo cuál traía como consecuencia que los temas a discutir constantemente pasaran a segundo plano. Lo relevante era lograr el mayor grado de persuasión y desacreditación ideológica de "los otros".

\section{ARGUMENTACIÓN FALAZ}

Durante las últimas décadas, los estudios sobre argumentación han experimentado un desarrollo cada vez más especializado, a tal grado que hoy día se considera un campo autónomo, gracias al esfuerzo interdisciplinario de analistas del discurso, filósofos, lógicos, analistas de la comunicación y de la conversación, entre otras disciplinas. ${ }^{2}$ En este trabajo sólo voy a considerar aquellos desarrollos teóricos enfocados a las argumentaciones que se construyen de manera interactiva en situaciones de controversia, bien, mediante intercambio de diálogos, o en textos escritos de contestación y refutación. Particularmente me adscribo a las propuestas teóricas que, desde una perspectiva pragmadialéctica, asumen especialistas como Grootendorst (2003), Anscombre y Ducrot (1988), Hamblin (1970). Las preguntas centrales intentan mostrar cómo es que puntos de vista contrarios en una discusión pueden llegar a estrechar posturas o a distanciarse más, en la medida en que se proponen nuevos argumentos. También se trata de saber cómo se utilizan estrategias retóricas para generar, en auditorios concretos, actitudes de solidaridad hacia el "nosotros" y rechazo hacia "ellos".

Precisamente, el corpus de estudio está conformado por muestras discursivas, donde las falacias argumentales constituyen el sustento persuasivo y retórico de las ideas que se defienden. Se trata de textos de orden político-religioso, publicados en 1873 , entre protestantes y católi-

${ }^{2}$ Para una revisión exhaustiva de los desarrollos en estudios y teorías sobre argumentación, el lector puede consultar el artículo de Pedro Reygadas y Julieta Haidar, titulado "Hacia una teoría integrada de la argumentación" (2001).

${ }^{3}$ Precisamente, un rasgo distintivo de sus propuestas es que la argumentación se estudia en planos de correferencia hacia un auditorio. En los estudios clásicos sobre argumentación, no se le daba a este aspecto una preponderancia tan relevante. Tal es el caso de las clasificaciones y el análisis del tratamiento de las falacias en el ámbito jurídico, emprendido en 1842 por Jeremy Bentham. 
cos que intentaban fervientemente defender sus respectivas religiones. De manera que el estudio será contrastivo.

En este trabajo analizaré el funcionamiento pragmático-discursivo de dos estrategias de argumentación falaz muy productivas en el corpus, y por lo demás, bastante comunes en textos orales de refutación y defensa, donde la discusión es exacerbada. Me refiero a la falacia de "ataque personal", también conocida por su nombre latino, como falacia ad hominem y a una de sus variantes, llamada "tú también", o por su nombre latino tu quoque.

Pero antes de entrar propiamente al análisis, me parece necesario reflexionar sobre la noción misma de falacia. Tradicionalmente se ha dicho que una falacia es "an argument that seems to be valid but that is not valid". (Van Eemeren y Grootendorst 2002). Esta definición inmediatamente puede ser cuestionada, ya que da cabida a numerosos cuestionamientos en torno a la subjetividad. Uno podría preguntar, por ejemplo, a partir de esta definición: ¿qué instancia, o quienes deciden si un argumento es válido o no lo es? También, esta noción de falacia parece determinar que los argumentos válidos y no válidos "existen" por sí mismos, cuando la práctica misma nos dice que la aceptación o rechazo de los argumentos depende también de factores contextuales, emotivos, y hasta de orden psicosocial. En ocasiones, un argumento falaz que parece no ser aceptable en cierta situación, puede ser aceptable en otra.

Desde un punto de vista estrictamente lógico, los llamados razonamientos circulares pueden considerarse válidos. Analistas de falacias como Govier (1982) y Broyles (1975) sostienen que las falacias no siempre merecen la "condena" de argumentos defectuosos, ya que bajo ciertas circunstancias comunicativas pueden funcionar como argumentos legítimos. Aquí entramos a un problema que puede ser circular, ya que podríamos considerar muchas circunstancias que pueden servir como atenuantes para que una falacia pueda ser considerada como válida o no válida. En consecuencia, parece que cada caso de falacias debe ser observado, a partir de sus propias circunstancias de referencialidad, y por lo tanto, no parece claro que exista un método general y del todo claro para distinguir entre argumentos falaces y no falaces.

Debido a las objeciones señaladas, considero necesario aclarar desde qué perspectiva entendemos una falacia. Desde una perspectiva lógica, 
una falacia puede verse como un tipo de razonamiento "deficiente". Pero desde una perspectiva pragmática, una falacia no necesariamente es deficiente, ya que puede cumplir funciones persuasivas. Si tomamos en cuenta estas dos perspectivas, podemos asumir que una falacia comporta un tipo de argumento "especial", ya que su función más importante es la de "hacer admitir" un razonamiento, y presentarlo como una buena vía para llegar a una conclusión determinada, por lo menos desde el punto de vista de quien comete la falacia (Escandell 1993).

El procedimiento implicará comparar sistemáticamente argumentaciones falaces en situación de disputa, entre textos de La Lanza de San Baltazar (protestantes) y La Religión y la Sociedad (católicos). En ambos periódicos encontramos características "especiales" de orden discursivo. Dichas características son las siguientes:

a) Aunque se trata de textos escritos, hay rasgos de oralidad muy importantes (Oesterreicher 1996). Lo hablado en textos se produce bajo condiciones de adscripción a ciertas tradiciones discursivas, que de manera muy compleja inciden en la conformación de los textos. Por tanto, habrá que tener en cuenta aspectos de dialogicidad, espontaneidad, fijación, determinación de los temas, etcétera. Aunque, debido a la distancia histórica, resulta muy difícil delimitar estos factores, propios de la contextualización oral. ${ }^{4}$

b) Se trata de textos "enmarcados" dentro del género epistolar por entregas, muy característico del siglo XIx. Un representante de la jerarquía católica escribe y un representante de la Iglesia reformada responde. El procedimiento también se da a la inversa.

\footnotetext{
${ }^{4}$ Respecto a la oralidad textual, es muy importante tener en cuenta, que no se trata de encontrar "lo hablado" en estado auténtico, pues, tal y como afirma el propio Oesterreicher, (1996, 323), "en una comunicación escrita nunca encontramos lo hablado en estado auténtico, puesto que la comunicación escrita implica, per definitionem, la existencia de unos valores paramétricos de las condiciones comunicativas que definen la 'distancia comunicativa'. Como ejemplo se pueden citar la 'separación local y distancia temporal de la producción y de la recepción del enunciado', 'exclusión de los contextos comunicativo paralingüístico y no-lingüístico, situativo y cognoscitivo individual', 'planificación y posibilidad de corregir el texto escrito', etc.".
} 
c) Aunque en el caso de la jerarquía católica, tenemos a un autor concreto (el presbítero Agustín de la Rosa), en realidad los destinatarios de los textos son colectivos, ya que la intención general no es interpelar las ideas de una persona en particular, sino cuestionar creencias y prácticas ideológicas ya instituidas por grandes grupos religiosos.

d) Se trata de textos muy polifónicos. ${ }^{5}$ En buena medida, el fundamento argumental depende de las referencias y citas que se hacen, tanto de autoridades eclesiásticas, como de textos sagrados.

e) En ambos discursos encontramos actos de habla "especiales", ya que el sentido conferido a ciertas acciones abstractas como hablar con Dios, suplicarle, interceder, condenarse, etcétera, es distinto al que comúnmente se confiere en actos de habla cotidianos (Camps 1976).

Estas cinco características generales hacen que el análisis necesariamente sea modesto y restrictivo. Al estudiar las falacias argumentativas, tendré en cuenta los aspectos anteriormente señalados, pero con las limitaciones propias de la distancia histórica, y la imposibilidad de "reconstruir", de un modo fiable, todos los aspectos de oralidad adyacentes a los textos.

EL ATAQUE PERSONAL

La primera falacia que considero, es aquella que se produce cuando el peso de un argumento no intenta refutar al argumento mismo, sino la credibilidad del oponente, bien, tratando de eliminar sus puntos de vista, o presentándolo como alguien poco inteligente, confiable, inconsecuente, sesgado, etcétera. Para designar cualquier forma de ataque personal se usa comúnmente la expresión latina argumentum ad hominem. ${ }^{6}$

${ }^{5}$ Utilizo el concepto de polifonía en el sentido en que lo desarrolla Oswald Ducrot (1986), es decir, como la pluralidad de voces externas al sujeto hablante, que un enunciado reúne y deja "oír". Esta teoría está enmarcada en la discusión clásica que intentaba colocar a un único autor como eje articulador de todo enunciado. Ducrot distingue por lo menos dos instancias diferenciadas al interior de los enunciados: un sujeto locutor y uno o varios enunciadores.

${ }^{6}$ John Locke en su libro An essay concerning human understanding (1961), utiliza por primera vez la expresión argumentum ad hominem como término técnico. De manera un 
Las motivaciones para atacar a la persona y no a sus ideas pueden ser múltiples y muy variadas. En el corpus recopilado son más frecuentes los ataques personales directos en La Lanza de San Baltasar, desde donde se formulan responsivas en contra del presbítero Agustín de la Rosa, quien, desde un principio es representado como alguien pretendidamente incapaz de sustentar argumentos veraces y coherentes, debido, entre otras razones, a su edad avanzada. De hecho, desde el encabezado mismo de la primera carta de respuesta, puede verse cómo los procedimientos argumentativos son presentados metafóricamente como un "ataque". ${ }^{7}$ Véase el inicio de la segunda carta publicada en contra de Agustín de la Rosa. ${ }^{8}$ La discusión versa sobre abusos por el cobro de servicios religiosos:

[1] "LANZAZOS SEGUNDACARTA

ALSR. DR. DN. A. DE LA ROSA.

Mi amado tata padre: Cumpliendo con lo que ofrecí á vd en mi número anterior, le escribo ahora nuevamente, esperando de su bondad, que no lo llevará á mal.

Enristro pues mi lanza, y 'en guardia, señor doctor'"' (La Lanza de San Baltazar, "Segunda carta al Sr. Dr. Dn. A. de la Rosa”, 29 de mayo de 1873, tomo I, núm. 2, p. 2)

tanto irónica, Van Eemeren y Grootendorst (op. cit. pp. 131) explican el funcionamiento de esta falacia como sigue: "En vez de patear la pelota, se patea al jugador".

${ }^{7}$ Lakoff y Johnson, en su famoso libro Metáforas de la vida cotidiana $(1995,41)$ proponen que las metáforas conceptuales que intervienen en discusiones se estructuran en términos bélicos. Tal vez uno de los aspectos más atractivos de esta perspectiva es que el sentido metafórico de "ataque" parece tan convencionalizado y estructurado en términos bélicos, que al parecer, ya forma parte de una serie de construcciones conceptuales que no necesariamente se utilizan de manera consciente. De ahí la siguiente afirmación de Lakoff y Johnson "La metáfora no está meramente en las palabras que usamos -está en nuestro concepto mismo de discusión".

${ }^{8}$ Cabe aclarar que, a diferencia de La Lanza de San Baltazar, en La Religión y la Sociedad los ataques no están dirigidos en contra de personas concretas debido a que en La Lanza de San Baltazar las notas no tienen firma de autor, de manera que quienes escribían en contra o a favor de ideas en este periódico, no tenían más recurso que dirigirse al periódico en general. 
Una estrategia de ataque personal se produce mediante marcadores discursivos de orden atributivo. Por ejemplo, constantemente se hace referencia a Agustín de la Rosa mediante los nominales viejito, tata, tati$t a$. En principio, esta clase de referencias sirven para singularizar negativamente la imagen de uno de los contendientes. ${ }^{9}$ Así, el locutor puede implicar que uno de los contendientes no está en plenas condiciones de argumentar razonablemente debido a que es un anciano. Desde el punto de vista argumentativo, la utilización de marcadores, como los mencionados, cumplen la función de topoi negativos, en el sentido en que lo entienden Anscombre y Ducrot (1998). De esta manera, el discurso puede "enmarcar" ciertas creencias y valoraciones que vinculan a la vejez con deficiencias cognitivas, como lentitud de razonamiento, incoherencia, desorden mental, etcétera. También se implica que alguien anciano es por naturaleza ingenuo, y por tanto, puede ser fácilmente engañado con ideas falsas, aún por sus propios correligionarios. ${ }^{10}$ Además, en el caso de La lanza de San Baltasar, el argumento falaz de ataque a la persona está reforzado con otra estrategia retórico-discursiva muy productiva en discursos de crítica. Me refiero a la ironía. En la siguiente muestra es notorio el juego irónico en el ataque ad hominem.

[2] Válame Dios, viejito yo no tengo el honor de conocer á vd., pero por lo que veo, juzgo tener fundamento para suponer a úd, un hombre demasiado crédulo y sencillo, supuesto que sus hermanos han hecho de vd, lo que unos malévolos hicieron en cierta vez con un buen cristiano, á quien le infundieron en la mollera que tenía trazas de ser buen torero. El pobre hombre, que tal cosa creyó, le salió á la fiera al encuentro[...]el toro le sacudió lindamente (La lanza de San Baltazar, "Segunda carta al Sr. Dr. Dn. A. de la Rosa", 29 de mayo de 1873, tomo I, núm. 2, p. 2)

\footnotetext{
${ }^{9}$ Violeta Demonte $(2000,172)$ define los nombres adjetivales como "términos atributivos cuya función es la de atribuir a las entidades propiedades que las describen y las singularizan".

${ }^{10}$ Destaco el hecho de que un marcador como viejito forma parte de un conjunto de rasgos de polaridad (viejo-joven). Sin embargo, en el contexto enunciativo del discurso en disputa, sólo se implican rasgos de polaridad negativa hacia "lo viejo".
} 
En el periódico católico, La Religión y la Sociedad también aparecen diversas variantes de la falacia ad hominem. Pero a diferencia de La Lanza de San Baltazar, los ataques no se dirigen a una persona en particular, sino al colectivo "los protestantes", presentado invariablemente como si fuera un grupo homogéneo, lo cual implica asumir, de entrada, un esquema argumentativo falaz (falacia por generalización), pues se da por sentado que al interior de grandes grupos religiosos sus miembros creen y actúan indistintamente de la misma manera y bajo cualquier circunstancia. Sin embargo, a pesar de que los protestantes aparecen como grupo homogéneo, constantemente se descubren "huellas" de especificidad negativa. Hay de fondo un sofisma recurrente, que se podría expresar como sigue: todos son iguales, pero con cualidades negativas muy diversas.

En efecto, las falacias de ataque personal que se realizan en este periódico adoptan diversas variantes. Es decir, el discurso intenta ponderar, de manera específica, todo un abanico de vicios, defectos y conductas negativas, que supuestamente son intrínsecos a la condición de protestante. De manera que la falacia ad hominem funciona mediante ataques "parcelados", cohesionados en divisiones y subdivisiones, que aleatoriamente se alternan, bien repitiéndose explícitamente o bien apareciendo en otro lugar, con otras estrategias enunciativas.

El primer argumento de ataque personal que encuentro en este periódico es de orden cualitativo. Los protestantes son mostrados como un grupo que ante todo, actúa por intereses económicos:

[3] Por otra parte, los protestantes que instigados vivamente por la sed de riqueza, han venido en abundancia á la América (La Religión y la Sociedad, "Primera contestación a los protestantes que han escrito en Guadalajara", 1873, p. 4)

Otra forma de desprestigio, consiste en mostrar a los protestantes como grupo incapaz de sostener argumentos de manera convincente, desde la perspectiva de quien escribe, pues se da por descontado que los protestantes están "fuera" de la verdad. Cuando esto sucede, es decir, cuando se da por sentado de antemano, que alguien no es capaz de argumentar adecuadamente porque algo intrínseco se lo impide, entonces estamos ante un intento de eliminar al interlocutor como un participante serio en la discusión. Este fenómeno se produce en ambas partes. Por 
ejemplo, en la siguiente muestra [4] se implica que los protestantes no son personas sinceras, dignas de fiar, ya que supuestamente sólo pueden argumentar mediante trampas, y recurriendo a juicios artificiosos. En esta muestra, el punto que se discute consiste en determinar si se debe promover o no la interpretación de los textos bíblicos, a partir de la lectura directa, tal y como sostienen los protestantes, o bien, si la interpretación "veraz" debe estar intercedida por la predicación de los sacerdotes, como sostienen los católicos.

[4] Se les ha dicho a los protestantes que el principio del libre exámen no es otra cosa sino decirle á la ignorancia «has una religión;» y á las pasiones, "sancionad vuestras leyes,» y que después de tantas disputas, variaciones y dudas, acaba el protestantismo por no reconocer doctrina ninguna. ¿Qué responden á esto? Absolutamente nada. Porque nada es posible responder, y en la imposibilidad de dar una respuesta ocurren al artificio de distraer la atención de los lectores. ¿Esto puede ser digno de hombres sinceros? ( $\mathrm{La}$ Religión y la Sociedad, "Primera contestación a los protestantes que han escrito en Guadalajara", 1873, p. 6)

La falta de sinceridad que se aduce en [4] forma parte de una serie continua de atributos negativos, casi siempre vinculados a otras atribuciones negativas como falta de honestidad, intereses ocultos, tergiversación de las "verdades" teológicas y el chantaje ideológico.

Otra variante del ataque a la persona, consiste en mostrar de principio, algo a favor del contrincante, pero de manera que inmediatamente se desvirtúe esa atribución favorable, mediante la presentación de un argumento en contra. Dicho argumento es personificador y señala una cualidad intrínsecamente negativa. En la siguiente muestra se da a entender que hubo algún momento histórico en el que los protestantes reconocían la necesidad de acercarse a los textos sagrados mediante la intercesión de intérpretes. Sin embargo, este hecho no prevaleció debido a la supuesta actitud rebelde y contestataria que los hacía estar permanentemente en contra de las autoridades católicas. ${ }^{11}$

${ }^{11}$ Según los historiadores Ruggiero Romano y Alberto Tenenti (1987), el señalamiento histórico de que la comunidad protestante no concibe intermediación en las interpre- 
[5] Los primeros protestantes reconocían la necesidad de ese medio seguro para alcanzar el verdadero sentido de las Escrituras; pero obstinados en negar la autoridad de la Iglesia, de quien se habían separado, no tuvieron otro recurso sino decir que El Espíritu Santo inspiraba á cada uno el verdadero sentido de las Escrituras; y ese fue el origen de la interpretación privada. ¡Miserables! Cuán pronto fueron desmentidos por los hechos (La religión y la Sociedad, "Primera contestación a los protestantes que han escrito en Guadalajara", 1873, p. 8)

En este caso se observa que el ataque personalizante, con el que se intenta sostener la desaprobación de la interpretación privada, se introduce a partir de la conjunción adversativa pero, la cual, en términos pragmáticos funciona como un marcador de sentido contrastivo (Schiffrin 1994) entre dos unidades ideacionales: "los primeros protestantes" y "aquellos que empezaron a negar la autoridad de la jerarquía católica". Es de notar cómo, a través de estas dos construcciones se intenta "proteger" a quien argumenta contra el peso de una evaluación adecuada, pues aunque en la construcción los primeros protestantes hay un cuantificador, aún así el rango de referencialidad es demasiado amplio, vago y genérico. ¿Se refiere a los primeros teólogos que secundaron el movimiento de Lutero? ¿Se refiere a los cristianos que en testimonio público se declararon en objeción contra el catolicismo, en la Dieta de Espira

taciones bíblicas tiene sus raíces en el humanismo crítico que floreció en la región norte de Europa. Ya mucho antes de que Lutero iniciara el movimiento de Reforma, precisamente en el noroeste de Europa, se habían desarrollado "algunos de los más poderosos elementos disolventes de la cristiandad medieval". Uno de estos elementos de desobediencia a la jerarquía romana consistía en fomentar el rechazo de los fieles a la obediencia pasiva, a no hacer caso cuando no se les predicaba de acuerdo con lo que está escrito en los textos bíblicos. Ambos historiadores sostienen que este entorno más "orgánico" y "autónomo" hacia la Escritura, sin mediadores, fue progresivamente afianzándose en el ámbito cotidiano, ya que suscitaba una relación de compromiso en la fe común. Citamos a los propios historiadores: $(1987,231)$ "En esta especie de nueva entrega al contacto directo -es decir, a la búsqueda del contacto- entre el hombre y Dios, el prestigio perdido por las instituciones tradicionales y el profundo descontento espiritual por ellas provocado, empujaban a los creyentes a poner, por lo menos, entre paréntesis a la Iglesia visible, y a intentar la realización de una renovada experiencia religiosa con sólo las propias fuerzas. La fe que salva, o la justificación por la fe predicada por Lutero, sería el decisivo catalizador de este proceso". 
(1529)? No sabemos. El hecho es que dada esta ambigüedad referencial en [5], el punto de vista en cuestión, no puede ser defendido o refutado de una manera concluyente. Finalmente, el ataque personalizante se refuerza mediante el calificativo exclamativo “imiserables!”.

\section{TU QUOQUE}

Otra variante de los argumentos de ataque a la persona se produce cuando se intenta exhibir una contradicción entre las ideas del oponente y sus acciones. Esta variante también se conoce a través de la locución latina tu quoque, cuya traducción sería "tú también" (Van Eemeren y Grootendorst op. cit., pp. 131). Mediante esta variante se intenta mostrar que la actitud del otro es hipócrita, ya que sin decirlo asume el mismo defecto que critica. En seguida mostramos un ejemplo. Se acusa a los protestantes de actuar, movidos por "sed de riqueza":

[6] Por otra parte, los protestantes que instigados vivamente por la sed de riqueza, han venido en abundancia á la América (La religión y la Sociedad, "Primera contestación a los protestantes que han escrito en Guadalajara", 1873 , tomo I, p. 4)

Veamos ahora la respuesta en La Lanza de San Baltazar:

[7] ¡A qué mi tata padre tan divertido, pues me hace reír! ¿O no produce entre nosotros la administración de sacramentos oro, pan y sueldos? ¿No existe en cada parroquia un arancel de derechos, que deben pagar los fieles, por los sacramentos que recibieren? ¿Y no es cierto que cuando se suele administrar gratis algún bautismo, por ejemplo, a algún pobre, se le hace entender que ha recibido una merced especial? (La Lanza de San Baltazar, Segunda carta al Sr. Dr. Dn. A. de la Rosa, 29 de mayo de 1873, núm. 2, p. 2)

Vemos que en [7] es muy marcada la implicación de inconsecuencia. El discurso ironizante trata de evidenciar que los católicos no son consecuentes con las críticas que hacen a los protestantes.

Por otra parte, una característica en las argumentaciones que encontramos en La Lanza de San Baltazar es el uso de reiteraciones expansivas. Se 
contraataca "devolviendo el tiro" varias veces y de manera tal, que la crítica no sólo incida sobre un aspecto negativo, sino sobre la mayor cantidad posible de aspectos que se consideran falsos, erróneos o manipuladores, desde el punto de vista de quien habla. Nótese cómo la seriación de las preguntas retóricas en [7] genera una sensación de agrupación no arbitraria, como si los aspectos criticados se produjeran simultáneamente sobre un mismo eje espacio temporal. También me parece que el sentido pragmático de las reiteraciones tiene un componente expansivo, ya que se intenta abarcar, de manera implícita, más aspectos de los que se mencionan.

Cabe señalar que en el corpus, la variante "tú también" de la falacia ad hominem, ocupa un lugar preponderante, pues con frecuencia protestantes y católicos se acusan mutuamente de "alterar" e interpretar a conveniencia los textos bíblicos, a fin de satisfacer intereses propios. Ya en la noción misma de "alterar" está implicado un cierto sentido de manipulación interesada. Veamos algunos ejemplos:

[8] ¿Cómo se atrevieron estos señores á decir públicamente en el escrito de que nos ocupamos anteriormente, que ellos no alteran la palabra de Dios? Ciertamente la alteran, y con premeditación, según les conviene para hacer que los incautos acepten sus errores como doctrinas reveladas por Dios ( $\mathrm{La}$ religión y la Sociedad, "Primera contestación a los protestantes que han escrito en Guadalajara", 1873, p. 13)

[9] pusieron como segundo mandamiento lo que realmente es explicación del primero, y además lo alteraron [...] Con lo dicho nos parece suficientemente demostrado que es falso que en nuestro catecismo de la Doctrina cristiana se hallan adulterado los Mandamientos de la ley de Dios, como pretendieron hacerlo creer los protestantes en el escrito absolutamente anónimo que fijaron en las calles de esta ciudad.-Presbítero Agustín de la Rosa (La religión y la Sociedad, "Primera contestación a los protestantes que han escrito en Guadalajara", 1873, pp. 15 y 16)

Ahora veamos un ejemplo tomado de La lanza de San Baltazar:

[10] SEÑOR. En vuestra segunda contestación, hablando de nuestra traducción del $2^{\circ}$ mandamiento asentais: "Esta versión castellana es viciosa, ya se compare con el texto latino ó ya con el griego, con el cual nos dicen que es- 
tán más conformes las biblias." Esta última aserción carece de verdad. Nuestra Biblia está más conforme con el "texto original," que con las traducciones griega y latina, á que vd. se refiere, las cuales son imperfectas en sí mismas (La Lanza de San Baltazar, Segunda réplica de los protestantes de Guadalajara, al presbítero D. Agustín de la Rosa, 20 de junio de 1873, tomo I, núm. 5, p. 1)

La ponderación de contradicciones y errores, pretendidamente intencionales, en lo referente a traducciones e interpretaciones de textos bíblicos es muy fructífera en ambos discursos, pues se trata de acusaciones "circulares" que pueden ser alimentadas indefinidamente, ya que en ambos bandos predomina un exacerbado solipsismo lingüístico, bajo el entendido de que interpretar un texto bíblico, no es un simple acto de racionalización semántica, sino la apropiación de una verdad sagrada. (Camps 1976).

Una peculiaridad contrastiva en la aplicación de tu quoque es la siguiente: Mientras que en el discurso de La Religión y la Sociedad las acusaciones por manipulación de traducciones suelen estar constreñidas al ámbito inmediato de la discusión, en La Lanza de San Baltazar dichas acusaciones se realizan mediante una estrategia de ataques "coextensivos". Consiste en devolver el ataque a partir de la misma falta señalada, pero de manera tal que la crítica no sólo recaiga en el interlocutor, sino también en otras autoridades católicas. Para ejemplificar tomaré uno, entre los numerosos puntos sometidos a discusión. En uno de estos puntos, ambas partes intentan sustentar la conveniencia, o no, de rendir culto a entidades sagradas a través de imágenes. Específicamente el punto a discusión está en la interpretación del capítulo 27, versículo 15, del Deuteronomio. Muestro en seguida ejemplos tomados de ambos periódicos, a fin de hacer notar la diferencia de estrategias argumentativas en la aplicación de la variante tu quoque.

[11] Nótese en segundo lugar que la traducción castellana de los Mandamientos que nos han dado los protestantes, tiene inexactitudes. Sólo nos ocuparemos de los siguientes. Esta versión castellana que nos presentan "No te harás imagen ni ninguna semejanza de cosa que esté arriba en el cielo, ni abajo en la tierra, ni en las aguas debajo de la tierra: No te inclinarás 
á ellas ni las honrarás," es viciosa ya se compare con el texto latino ó ya con el griego, con el cual nos dicen que están mas conformes sus Biblias (La religión y la Sociedad, "Segunda contestación a los protestantes que han escrito en Guadalajara", 1873, p. 12)

Como se aprecia, la acusación está constreñida al colectivo "los protestantes". No así en la siguiente muestra tomada de La Lanza de San Baltazar.

[12] Nos acusais de haber mal traducido del griego y del latin ciertas palabras del 2.o mandamiento. En primer lugar, nuestra Biblia no ha sido traducida de estas versiones; pero admitiendo que lo hubiera sido, como lo afirmáis, y tomásemos, "sculptile" por imagen; "proscuneo," por inclinar y "latruo" por honrar; si leéis la traducción de Scio, aprobada por la Iglesia Romana, hallaréis que él ha cometido la misma falta, pues en el Deut. cap. 27, ver. 15, tradujo la palabra latina "sculptile" por imagen: "Maldito el hombre que hace imagen (sculptile) de talla ó de fundición, abominación del Señor, obra de manos de artífices" [...] $\underline{\text { Si pues condenáis la traducción de los }}$ protestantes respecto de esas palabras, condenáis al mismo tiempo á Scio que muy frecuentemente las estima como nosotros; y aun hacéis mas: condenáis también al infalible Papa, pues él ha sancionado la traducción de Scio. (La Lanza de San Baltazar, Segunda réplica de los protestantes de Guadalajara, al presbítero D. Agustín de la Rosa, 20 de junio de 1873, tomo I, núm. 5, p.1)

Me parece relevante destacar que en casos como en [12], la coextensión de la crítica, va más allá de un cuestionamiento de traducción textual. Se trata de hacer notar que las alteraciones intencionales, en el nivel léxico, no son superficiales, sino que forman parte de un sistema mucho más complejo, fuera del alcance de la discusión. En ambos discursos, parece claro que mediante el uso de la falacia ad hominem, además de cuestionar y desacreditar las creencias de "los otros", se intenta reforzar la credibilidad propia. El tema del argumento pasa a segundo plano, ya que para los contendientes, lo más relevante será lograr el mayor grado de desacreditación posible de "los otros".

Ahora bien, no me ha parecido adecuado abordar una falacia, de acuerdo con la noción tradicional que trataba de explicarla simplemen- 
te como un argumento no válido. Esa noción no contempla el problema de la perspectiva. He constatado en ambos periódicos que precisamente la validez de los argumentos propios es muy contrastiva, ya que para el grupo desde el cual se habla, algunos presupuestos sólo son válidos en la medida en que no se consideran válidos los argumentos del grupo contrario. Tal es el caso, como ya hemos visto anteriormente, de los argumentos que se esgrimen en La Lanza de San Baltazar y en La Religión y la Sociedad para defender o rechazar el culto a entidades sagradas, a través de "imágenes". Estamos ante un problema complejo de valoración endógena.

Considero que el problema de la perspectiva de valor puede ser integrado a la perspectiva pragmática de las falacias. Una falacia ad hominem puede verse como una "violación" a la regla tres (sea relevante), de los principios de cooperación de Grice (1975), pero esa violación también es relativa a un punto de vista contrastivo: ¿quién fija la relevancia?, ¿respecto a qué? El problema no es simple y al parecer no puede resolverse de manera satisfactoria para todos los casos. De cualquier manera, lo que se constata es que los ataques personales en las notas analizadas forman parte de un conjunto de procedimientos de valoración e identificación intersubjetiva. Estamos ante argumentos falaces que no pueden ser analizados como simples intentos pragmáticos de refutación, sino como estrategias de transgresión y refuerzo ideológico.

\section{CONCLUSIONES}

Hemos constatado que los procedimientos de discusión, refutación y constatación verificativa en los discursos del corpus analizado, se llevan a cabo, en buena medida, mediante argumentos falaces que aún y cuando pueden ser vistos desde una perspectiva lógica, como razonamientos "deficientes", también es un hecho que desde una perspectiva pragmática, esos mismos argumentos falaces cumplen un papel muy importante en la transmisión persuasiva de mensajes polarizados. En el corpus se hace evidente que una de las falacias más reiteradas es la de ataque personal, o falacia ad hominem. Mediante esta falacia era posible generar un "movimiento" del foco argumentativo, de manera que lo importante ya 
no era el contenido mismo de las argumentaciones, sino la fuerza de los ataques y el desprestigio que se lograra conseguir de los otros. En nuestro corpus son más frecuentes los ataques personales en La Lanza de San Baltasar. En el periódico católico, La Religión y la Sociedad también encontramos diversas variantes de la falacia ad hominem, pero a diferencia de La Lanza de San Baltazar, los ataques no se dirigen a una persona en particular, sino al colectivo "los protestantes", presentado invariablemente como si fuera un grupo homogéneo. Este hecho es contradictorio, pues de manera reiterada se descubren numerosas "huellas" de especificidad negativa, mediante un recurso sofístico que podríamos expresar como sigue: todos son iguales, pero con cualidades negativas muy diversas. Se trata de ingresar al terreno de la especificidad exhaustiva. Mostrar todo un abanico de vicios, defectos y conductas negativas, que pretendidamente debían ser intrínsecos a la condición de protestante. De manera que la falacia ad hominem funciona mediante ataques "parcelados", cohesionados en divisiones subdivisiones que podían alternarse aleatoriamente, ya sea repitiéndose explícitamente o apareciendo en otro lugar, con otras estrategias enunciativas. ${ }^{12}$

En La Religión y la Sociedad, los intentos de desprestigio, en términos generales, están dirigidos a mostrar que los protestantes actúan motivados ante todo por intereses económicos, pero sobre todo se trata de mostrarlos como grupo disidente, subversivo y falsario ideológicamente, ya que se implica que están "fuera" de la verdad. También se implica que los protestantes no son personas sinceras y dignas de confianza, ya que que supuestamente sólo pueden argumentar mediante trampas, y recurriendo a juicios artificiosos.

Por otra parte se hace evidente que la falacia ad hominem era utiliza$\mathrm{da}$, en algunos casos como instrumento de crítica coextensiva, de manera tal que la crítica no sólo recayera en el interlocutor, sino en otras autoridades religiosas. Esta estrategia aparece de manera más reiterada en el periódico católico. Finalmente he constatado que las estrategias de de-

\footnotetext{
${ }^{12}$ Para Foucault, cuando un discurso incide de manera incisiva sobre las conductas y los comportamientos de los otros, tratando de infiltrarse, descalificando, incitando, e intensificando la crítica, eso forma parte de lo que él llama las "técnicas polimorfas del po$\operatorname{der}^{\prime \prime}(2000,19)$.
} 
fensa y ataque estaban integradas a un conjunto mayor de procedimientos valorativos, donde, de manera crucial interviene la identificación ideológica.

\section{REFERENCIAS}

Anscombre, Jean-Claude y Oswald Ducrot, La argumentación en la lengua, Madrid, Ed. Gredos, 1988.

BENTHAM, Jeremy, Works (published under the superintendence of his executor), John Bowring, ed., vol. II, Edinburgh, William Tait, 1843 en 11 volúmenes.

BRoYLes, J.E. "The fallacies of composition and division", en Dialogue, 15, 1975, 241-255.

CAmPS, Victoria, Pragmática del lenguaje y filosofía analítica, Barcelona, Ediciones Península, 1976.

Demonte, Violeta, "El adjetivo: clases y usos. La posición del adjetivo en el sintagma nominal", en Gramática Descriptiva de la Lengua Española, Tomo 1 (1999), Madrid, Real Academia Española, Ed. Espasa Calpe, $3^{\mathrm{a}}$ reimpresión, 2000, 129-393.

Ducrot, Oswald, El decir y lo dicho. Polifonía de la enunciación, Barcelona, Paidós Ibérica, 1986

DorANTES, Alma, "La llegada del evangelio protestante", en Los "otros" hermanos (minorías religiosas protestantes en Jalisco), Guadalajara, Editado por la Secretaría de Cultura, Gobierno del Estado de Jalisco, 2005.

EsCANDELl VIDAL, M. Victoria, Introducción a la pragmática, Barcelona, Ed. Anthroopos, Universidad Nacional de Educación a Distancia, 1993.

Foucault, Michel, Historia de la sexualidad, Vol. 1 La voluntad de saber, México, Ed. Siglo XXI, 2000.

Grice, Paul, "Logic and conversation", en Syntax and Semantics 3, Speech Acts, Nueva York, Academic Press, 1975.

GOVIER, T. "What's wrong with slippery slope arguments", en Canadian Journal of Philosophy, 12, 1982, 303-316.

GROOTENDORST, R., Systematic Theory of Argumentation: The Pragma-Dialectical Approach, West Nyack, Cambridge University Press, 2003. 
Hamblin, Christopher. L., Fallacies, Londres, Methuen, 1970.

LAKOFF, George y Mark JoHnson, Metáforas de la vida cotidiana (1980), Madrid, Ed. Cátedra, $3^{\text {a }}$. Edición, 1995.

LOCKE, John, Of Reason. In: An Essay Concerning Human Understanding, book IV, chapter XVII, 1690. J. W. Yolton (ed.), Londres, Dent, 1961.

OeSTERREICHER, Wulf, “Lo hablado en lo escrito. Reflexiones metodológicas y aproximación a una tipología", en El español hablado y la cultura oral en España e Hispanoamérica, en: Thomas Kotschi, Wulf Oesterreicher y Klaus Zimmermann (eds.), Bibliotheca Iberoamericana núm. 59, Frankfurt am Main: Vervuert; Madrid, Iberoamericana, 1996, 588 p.

ReYGaDAs, Pedro y Julieta HaIDAR, "Hacia una teoría integrada de la argumentación", en Estudios sobre las culturas contemporáneas, Época II, vol. vII, núm. 13, Colima, junio 2001, 107-139.

Romano, Ruggiero y Alberto Tenenti, Historia universal, Siglo XXI (los fundamentos del mundo moderno), núm. 12, México, Ed. Siglo XXI, 1987.

Schiffrin, Deborah, Discourse markers, Newcastle upon Tyne, Athenaeum Press Ltd, 1994.

Téllez Aguilar, Abraham, "Protestantismo y política en México, en el Siglo XIX", en Laura Espejel López y Rubén Ruiz Guerra, El Protestantismo en México (1850-1940). La Iglesia Metodista Episcopal, México, INAH, 1995.

Van Eemeren, Frans y Rob Grootendorst, Argumentación, comunicación y falacias (una perspectiva pragma-dialéctica), (1992), Santiago de Chile, Ediciones Universidad Católica de Chile, 1ª . edición, 2002.

Periódicos consultados

La lanza de San Baltazar, Guadalajara, México, tomo I, 1873.

La religión y la Sociedad, Guadalajara, México, 1873.

FECHA DE RECEPCIÓN DEL ARTículo: 6 de febrero de 2009

FECHA DE ACEPTACIÓN Y RECEPCIÓN DE LA VERSIÓN FINAL: 10 de octubre de 2010 